\title{
Study of indoor PM2.5 distribution characteristics and optimal location for its monitoring in an office
}

\author{
Guoxiang Hong ${ }^{1,2}$, Chunhui Liao ${ }^{1,2}$, Hong Liu ${ }^{1,2}$ \\ ${ }^{1}$ Joint International Research Laboratory of Green Buildings and Built Environments (Ministry of Education), Chongqing University, \\ Chongqing 400045, China \\ ${ }^{2}$ National Centre for International Research of Low-carbon and Green Buildings (Ministry of Science and Technology), Chongqing \\ University, Chongqing 400045, China
}

\begin{abstract}
With the appearance of the word "haze" in China, PM2.5 (particulate matter with aerodynamic diameter less than $2.5 \mu \mathrm{m}$ ) that can enter occupants' lungs has become a public topic of discussion. Today, the indoor PM2.5 or fine particulate concentration has become one of important factors affecting indoor air quality (IAQ). How to properly monitor indoor PM2.5 is an urgent issue to be discussed and solved. At present, sampling is adopted to know PM2.5 concentration in a room, and Chinese related standard required the sampling time for indoor PM2.5 is at least 8 hours. However, the sampling method takes too much time, and the HVAC system cannot react in real time such as increasing the fresh air volume with increase of indoor PM2.5 concentration. So, there is a great need to find an optimal location for continuous PM2.5 monitoring. Before finding the monitoring point, the spatial and temporal distribution characteristics of indoor PM2.5 concentration are needed to be known. Computational fluid dynamics (CFD) can be used to simulate airflow and dispersion of PM2.5 in rooms with different scales, functions and ventilations. This paper will contribute to find the optimal location which could preferably describe indoor PM2.5 concentration in an office combined with experimental research and CFD simulation. In short, the aim of the paper is to reveal the spatial-temporal characteristics of indoor PM2.5 concentration distribution and optimize the layout of PM2.5 monitoring points for air conditioning systems to better control indoor contaminate PM2.5 concentration.
\end{abstract}

\section{Introduction}

The first time that the U.S. environmental protection agency (USEPA) ${ }^{[1]}$ established PM2.5 was in 1997 to protect public health. Due to the rapid industrialization and high energy consumption, PM2.5 pollution is gradually exploding. It can increase the incidence of various respiratory diseases and occupant mortality rates, as well as increase of the energy consumption in heating, ventilation, and air conditioning (HVAC) systems. However, nowadays people have spent as much as $80 \%$ to $90 \%$ hours indoors, such homes, offices, and transport vehicles $^{[2-4]}$. Meanwhile, indoor air quality (IAQ), which have a directly significant influence on health as well as efficiency of study and work ${ }^{[5-7]}$, is becoming worse and worse. To solve the problem produced by indoor PM2.5, it is essential to study the indoor PM2.5 concentration distribution characteristics.

Since PM2.5 attached public attention, many researchers studied on indoor PM2.5. People, who have jobs, spend most time of their day in the office, and there are many sources that produce particulate matter such as outdoor sources, human activities, printer and other electrical appliances. This study combines experimental research and CFD simulation to the spatial and temporal distribution characteristics of indoor PM2.5 concentration in an office. Some previous works have done some studies on particle emissions and its concentration of printers in the office room ${ }^{[8,9]}$. And other works used the CFD to simulate indoor PM2.5 distribution in different ventilated ways ${ }^{[10-16]}$. But, there are few studies to find the optimal location for monitoring, so, this is where this study is deserved.

This study focused on the indoor PM2.5 distribution characteristics and optimal location for its monitoring in an office. The indoor PM2.5 concentration deserved to study deeply, not only to find the optimal monitoring location, and for the occupants' and workers' health. Although the analysis about indoor PM2.5 distribution and the selection of monitoring location in this paper may be superficial, it is meaningful to start studies in this field of indoor PM2.5.

\section{Experimental method}

\subsection{Monitoring site}

A typical office in Chongqing University was chosen as the monitoring site.

\subsection{Instrumentation}


PM2.5 concentration was measured by laser sensor produced by Panteng Company in China, table 1 shows its performance parameter.

Table 1. characteristics of PM2.5 sensor

\begin{tabular}{ccc}
\hline Parameter & Index & Unit \\
\hline Particle measurement range & $\mu \mathrm{m}$ \\
Particle count efficiency & $0.3-1.0 ; 1.0-2.5 ; 2.5-10$ & \\
Particle mass concentration effective range & $50 \% @ 0.3 \mu \mathrm{m} 98 \% @ \geq 0.5 \mu \mathrm{m}$ & $\mu \mathrm{g} / \mathrm{m}^{3}$ \\
(PM2.5 standard value) & $0-500$ & $\mu \mathrm{g} / \mathrm{m}^{3}$ \\
Particle mass concentration resolution & 1 & $\mathrm{~L}$ \\
Particle mass concentration consistency & $\pm 10 \% @ 100-500 \mu \mathrm{g} / \mathrm{m}^{3}$ & $\mathrm{~s}$ \\
(PM2.5 standard value) & $\pm 10 \mu \mathrm{g} / \mathrm{m}^{3} @ 0-100 \mu \mathrm{g} / \mathrm{m}^{3}$ & 0.1 \\
Weighing volume & $<1$ & $\mathrm{~s}$ \\
Single response time & $\leq 10$ & \\
Integrated response time & & \\
\hline
\end{tabular}

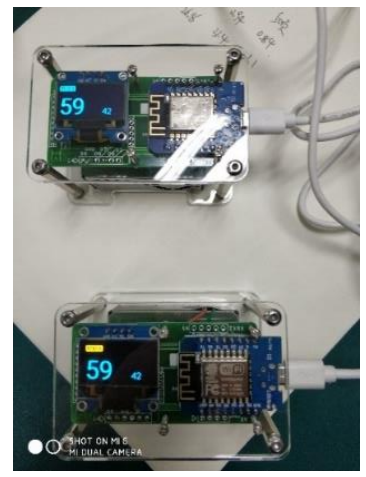

Figure 1. Laser sensor for PM2.5 monitoring

Temperature data acquisition was obtained with the Agilent 34980A Multifunction Intelligent Data Collector with a T-type thermocouple. In order to ensure the accuracy of the data, the thermocouple is calibrated using the constant temperature water tank method.

The wind speed data of the supply and return air is collected by the Swema 3000 anemometer. The measurement method of wind speed refers to the "Code for Construction Technology and Quality Acceptance of Ventilation and Air Conditioning Engineering" GB 50019-2003, which adopts the fixed-point measurement method.

Source of PM2.5 in this study is incense. The burnout time of the incense is about three hours, and the emission rate of PM2.5 is $5.33 \mu \mathrm{g} / \mathrm{m}^{3}$.

\subsection{Arrangement of PM2.5 monitoring point}

In this experiment, there are ten locations for PM2.5 monitoring totally. Five locations are in the space and other five points are near the ceiling or the west wall. The five points in the space are evenly distributed across the diagonal and their height is $1.2 \mathrm{~m}$ in the breathing zone. The other five points are $0.1 \mathrm{~m}$ away from the wall or ceiling and the specific arrangement for these points is shown in Figure 2.

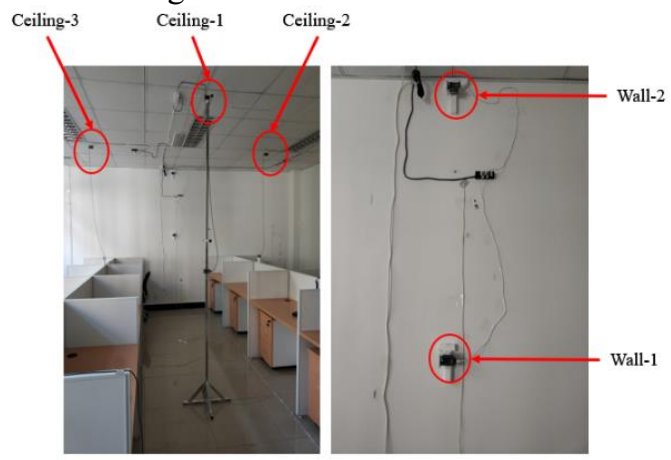

Figure 2. Arrangement for 5 points near the ceiling or west wall

\subsection{Data processing and analysis}

All statistical analyses (correlation, regression, t-test) were conducted using Excel (Microsoft). When the distribution of the data was not a normal distribution, the robust analysis (trim off the maximum and minimum) was employed.

\section{CFD modeling}

\subsection{Model for an office established}

According to the structure parameters of the room in actual engineering, the simulation model on the distribution of PM2.5 in indoor air is established in the condition of air conditioning. Figure 3 shows the office model in the air conditioning ventilation and specifications of the office are listed in Table 2. The model is based on the actual room size, meanwhile some indoor display was simplified. 


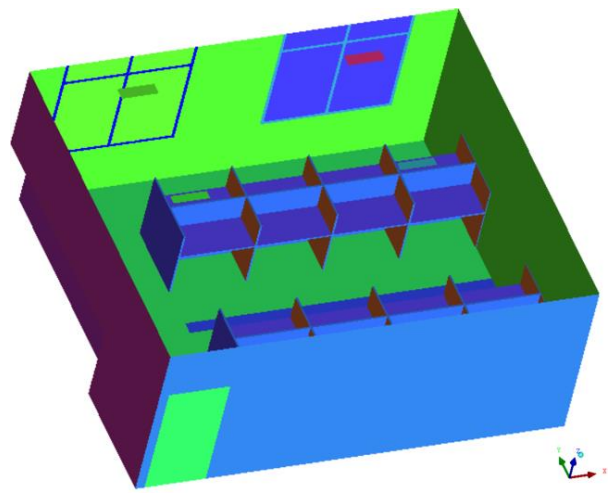

Figure 3. A schematic view the office used for full-scale experiments and simulations

Table 2. Specifications of the office

\begin{tabular}{|c|c|c|c|c|c|}
\hline \multirow[t]{2}{*}{ Ventilation } & \multicolumn{3}{|c|}{ Dimensions(m) } & \multirow{2}{*}{$\begin{array}{l}\text { velocity of supply vent } \\
(\mathrm{m} / \mathrm{s})\end{array}$} & \multirow{2}{*}{$\begin{array}{c}\text { Particle size } \\
\mu \mathrm{m}\end{array}$} \\
\hline & Length & Width & Height & & \\
\hline Ceiling supply (fan coil) & 7 & 6 & 2.9 & 5 & $\leqslant 2.5$ \\
\hline
\end{tabular}

\subsection{Simulation method}

In this study, the ANSYS 15.0 was adopted to analyze the indoor PM2.5 distribution characteristics. Considering forces on the PM2.5, the Basset history, the pressure gradient and the virtual mass are ignored because they are infinitesimal and negligible compared to the drag force ${ }^{[12]}$. Meanwhile the PM2.5 is assumed to be the spherical particulate matters with a diameter less than $2.5 \mu \mathrm{m}^{[14]}$. This paper adopts the Euler-Lagrange model to track the movements of PM2.5. The continuous phase uses the k- $\varepsilon$ turbulence model to couple calculation with discrete phase. However, the standard k- $\varepsilon$ turbulence model and the Realizable k- $\varepsilon$ turbulence model were both adopted in different studies of indoor PM2.5. So, this paper will make comparison of two $\mathrm{k}-\varepsilon$ turbulence models and obtain the optimal model for the office. In this simulation, the coupling calculation with discrete will be occurred when the continuous phase is calculated every two iteration step. For the analyses about the indoor PM2.5 concentration distribution characteristics, the inlet of the office adopts the velocity boundary for the continuous phase. At the same time, the escape boundary for the discrete phase is adopted in that. The outlet adopts the standard k- $\varepsilon$ turbulence model

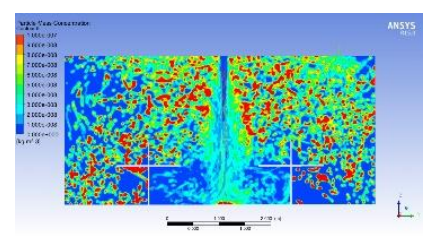

$\mathrm{X}=5.2 \mathrm{~m}$ outflow boundary for the continuous phase and the escape boundary for the discrete phase. In addition, the wall, floor, ceiling adopt trap boundary for the discrete phase.

\subsection{Result of simulations and discussion}

Figure 4 depicts the mass concentration distribution of indoor PM2.5 at different section of $X=5.2 \mathrm{~m}, \mathrm{Z}=1.2 \mathrm{~m}$, $\mathrm{Z}=$ ceiling under two different turbulence models. The results show that the indoor PM2.5 diffuses uniformly in the standard $\mathrm{k}-\varepsilon$ turbulence model, especially in the $\mathrm{Z}=$ ceiling. So, the standard $\mathrm{k}-\varepsilon$ turbulence model could describe indoor PM2.5 dispersion better for the office model. Figure 5 shows three counters of PM2.5 mass concentration under the standard k- $\varepsilon$ turbulence model. In Figure 5, the mass concentration of PM2.5 in $X=3.5 \mathrm{~m}$ is larger than the mass concentration in $X=5.2 \mathrm{~m}$ located around inlet, so the indoor PM2.5 concentration is directly influenced by velocity. At the same time, these results indicate that the optimal location for PM2.5 monitoring could be found to represent the mean value of indoor PM2.5 concentration in the breathing zone.

Realizable k- $\varepsilon$ turbulence model

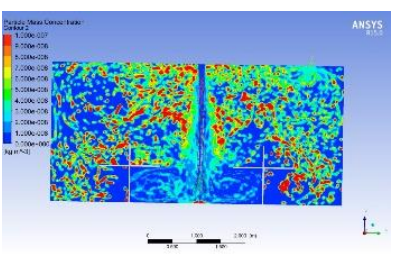

$\mathrm{X}=5.2 \mathrm{~m}$ 


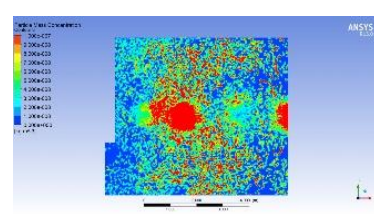

$\mathrm{Z}=1.2 \mathrm{~m}$

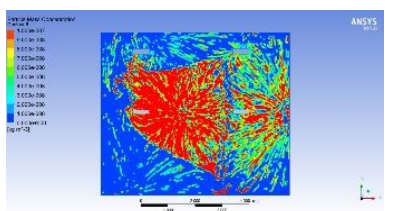

$\mathrm{Z}=$ ceiling

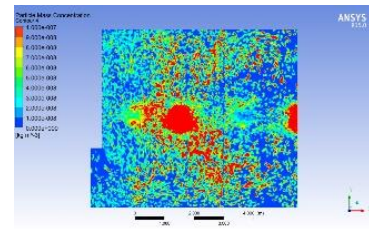

$\mathrm{Z}=1.2 \mathrm{~m}$

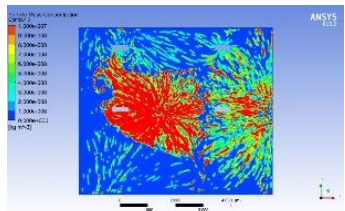

$\mathrm{Z}=$ ceiling

Figure 4. Comparison of simulation results about indoor PM2.5 concentration distribution in three vertical views

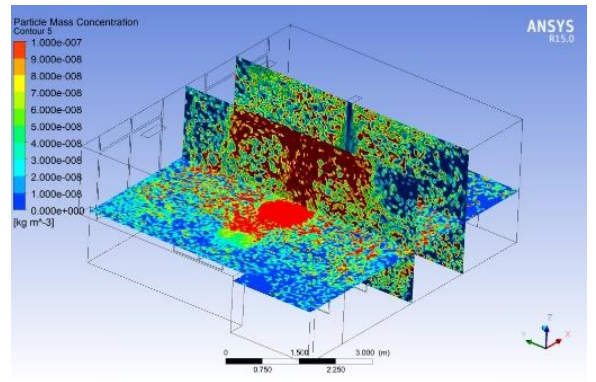

Figure 5. Counters of PM2.5 concentration in standard k- $\varepsilon$ turbulence model

\section{Experimental results and discussion}

\subsection{Experimental conditions and results}

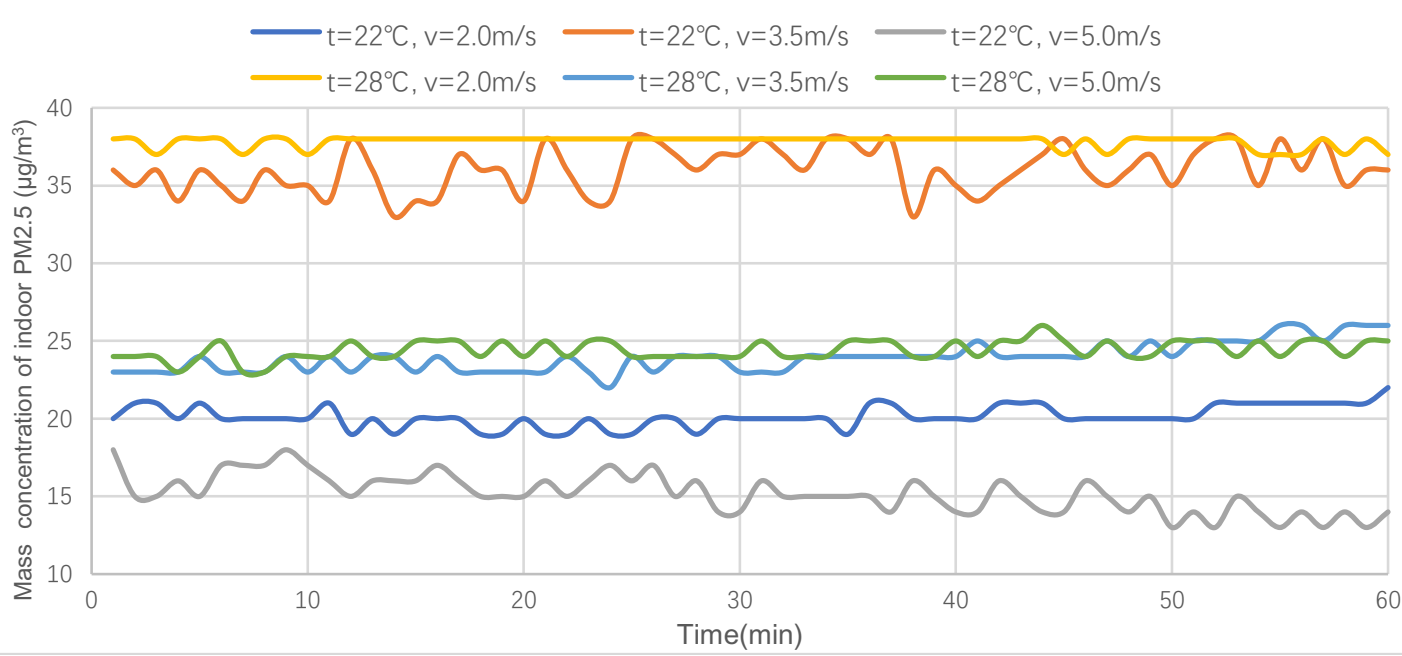

Figure 6. Mean value of background PM2.5 concentration in 6 conditions (no sources and fresh air supply)

Experiment in the office has eight conditions. The six conditions monitor the background mass concentration of PM2.5 with three different velocity $(2.0 \mathrm{~m} / \mathrm{s}, 3.5 \mathrm{~m} / \mathrm{s}, 5.0$ $\mathrm{m} / \mathrm{s})$ and two different temperature $\left(22\right.$ and $\left.28^{\circ} \mathrm{C}\right)$ in inlet. One condition combines the fan coil and fresh air with the velocity $=5.0 \mathrm{~m} / \mathrm{s}$ and temperature $=22{ }^{\circ} \mathrm{C}$ in inlet. Another condition burns the incense for the PM2.5 source with the velocity $=5.0 \mathrm{~m} / \mathrm{s}$ and temperature $=22{ }^{\circ} \mathrm{C}$ in inlet and no fresh air. Figure 6 shows curves of mean PM2.5 concentration of five points in space under 6 conditions with 60 minutes when the air conditioning is stable. Figure 7 depicts that the mean PM2.5 concentration in space and other PM2.5 concentration near the ceiling and wall changes with time after the air conditioning is opened in two hours. 


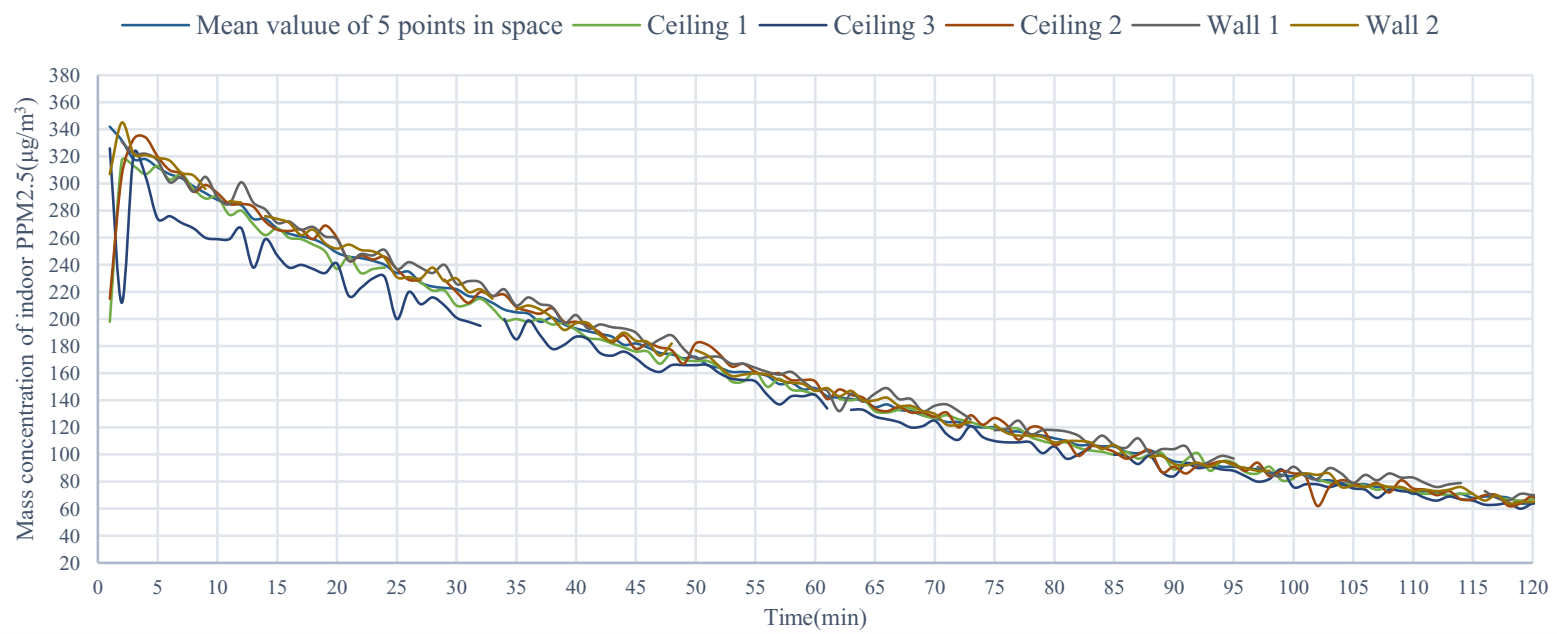

Figure 7. Comparison of mean PM2.5 concentration in space and other 5 point's PM2.5 concentration near ceiling and wall

\subsection{Discussion}

Figure 6 shows that mean mass concentration of indoor PM2.5 is steady if there is no evident source which can generate PM2.5. The indoor PM2.5 concentration has a great correlation with the outdoor PM2.5 concentration, which can be known by Figure 6, where the outdoor PM2 .5 concentration is larger in " $\mathrm{t}=22^{\circ} \mathrm{C}, \mathrm{v}=3.5 \mathrm{~m} / \mathrm{s}$ " and " $\mathrm{t}=28{ }^{\circ} \mathrm{C}, \mathrm{v}=2.0 \mathrm{~m} / \mathrm{s}$ " than in other conditions. Figure 7 shows that the mean value of indoor PM2.5 in space is similar with the indoor PM2.5 concentration near ceiling or wall. So, it indicates that the 5 locations near ceiling and wall can represent the mean value in space in some extent again.

This study makes the comparison between indoor PM2.5 concentration of 5 points near the ceiling and wall with the mean value of PM2.5 concentration in space. Table 3 shows the deviation of location near ceiling or wall from the mean value. Ceiling 3 , ceiling 3 , ceiling 1 perform better in the velocity $=2.0 \mathrm{~m} / \mathrm{s}, 3.5 \mathrm{~m} / \mathrm{s}, 5.0 \mathrm{~m} / \mathrm{s}$ respectively.

Table 3. Deviation of location near ceiling or wall from the mean value

\begin{tabular}{|c|c|c|c|c|c|}
\hline \multicolumn{6}{|c|}{ Deviation from the mean value [mean value of deviation (minimum value of deviation, maximum value of deviation) ] } \\
\hline & \multicolumn{5}{|c|}{ Velocity $=2.0 \mathrm{~m} / \mathrm{s}$} \\
\hline Temperature & Ceiling 1 & Ceiling 2 & Ceiling 3 & Wall 1 & Wall 2 \\
\hline $22^{\circ} \mathrm{C}$ & $-0.27 \%(-9.52 \%, 10.53 \%)$ & $-2.86 \%(-10.00 \%, 10.53 \%)$ & $-1.25 \%(-14.29 \%, 15.79 \%)$ & $6.45 \%(-4.76 \%, 26.32 \%)$ & $0.58 \%(-14.29 \%, 10.53 \%)$ \\
\hline \multirow[t]{2}{*}{$28^{\circ} \mathrm{C}$} & $-5.76 \%(-10.53 \%, 0.00 \%)$ & $-6.47 \%(-10.53 \%,-2.63 \%)$ & $-3.96 \%(-10.53 \%, 0.00 \%)$ & $-3.21 \%(-7.89 \%, 2.70 \%)$ & $-11.4 \%(-15.79 \%,-5.41 \%)$ \\
\hline & \multicolumn{5}{|c|}{ Velocity $=3.5 \mathrm{~m} / \mathrm{s}$} \\
\hline Temperature & Ceiling 1 & Ceiling 2 & Ceiling 3 & Wall 1 & Wall 2 \\
\hline $22^{\circ} \mathrm{C}$ & $-6.75 \%(-11.43 \%,-2.86 \%)$ & $-3.66 \%(-11.43 \%, 2.86 \%)$ & $-0.35 \%(-5.71 \%, 5.88 \%)$ & $4.84 \%(-2.86 \%, 9.09 \%)$ & $-7.05 \%(-11.43 \%,-2.86 \%)$ \\
\hline \multirow[t]{2}{*}{$28^{\circ} \mathrm{C}$} & $-0.13 \%(-8.70 \%, 13.64 \%)$ & $-4.24 \%(-12.50 \%, 8.70 \%)$ & $-2.16 \%(-12.50 \%, 4.55 \%)$ & $-1.22 \%(-12.50 \%, 8.70 \%)$ & $-6.46 \%(-12.50 \%, 0.00 \%)$ \\
\hline & \multicolumn{5}{|c|}{ Velocity $=5.0 \mathrm{~m} / \mathrm{s}$} \\
\hline Temperature & Ceiling 1 & Ceiling 2 & Ceiling 3 & Wall 1 & Wall 2 \\
\hline $22^{\circ} \mathrm{C}$ & $0.16 \%(-14.29 \%, 14.29 \%)$ & $-3.51 \%(-14.29 \%, 7.69 \%)$ & $-2.37 \%(-14.29 \%, 14.29 \%)$ & $3.95 \%(-7.14 \%, 20.00 \%)$ & $-3.88 \%(-15.38 \%, 13.33 \%)$ \\
\hline $28^{\circ} \mathrm{C}$ & $-2.68 \%(-16.00 \%, 12.50 \%)$ & $-2.73 \%(-12.00 \%, 8.33 \%)$ & $-1.80 \%(-16.00 \%, 8.33 \%)$ & $-0.83 \%(-12.00 \%, 8.33 \%)$ & $-7.20 \%(-16.00 \%, 0.00 \%)$ \\
\hline
\end{tabular}

Condition 7: combing fan coil and fresh air with the velocity $=5.0 \mathrm{~m} / \mathrm{s}$ and temperature $=22^{\circ} \mathrm{C}$ in inlet. Figure 8 shows that mass concentration of PM2.5 near ceiling or wall and mean PM2.5 mass concentration of 5 points in space have a good correlation. The point "Ceiling 1" performs the best correlation among 5 points, which can be seen from Table 4 and its value of $\mathrm{R}^{2}$ is 0.8854 . 


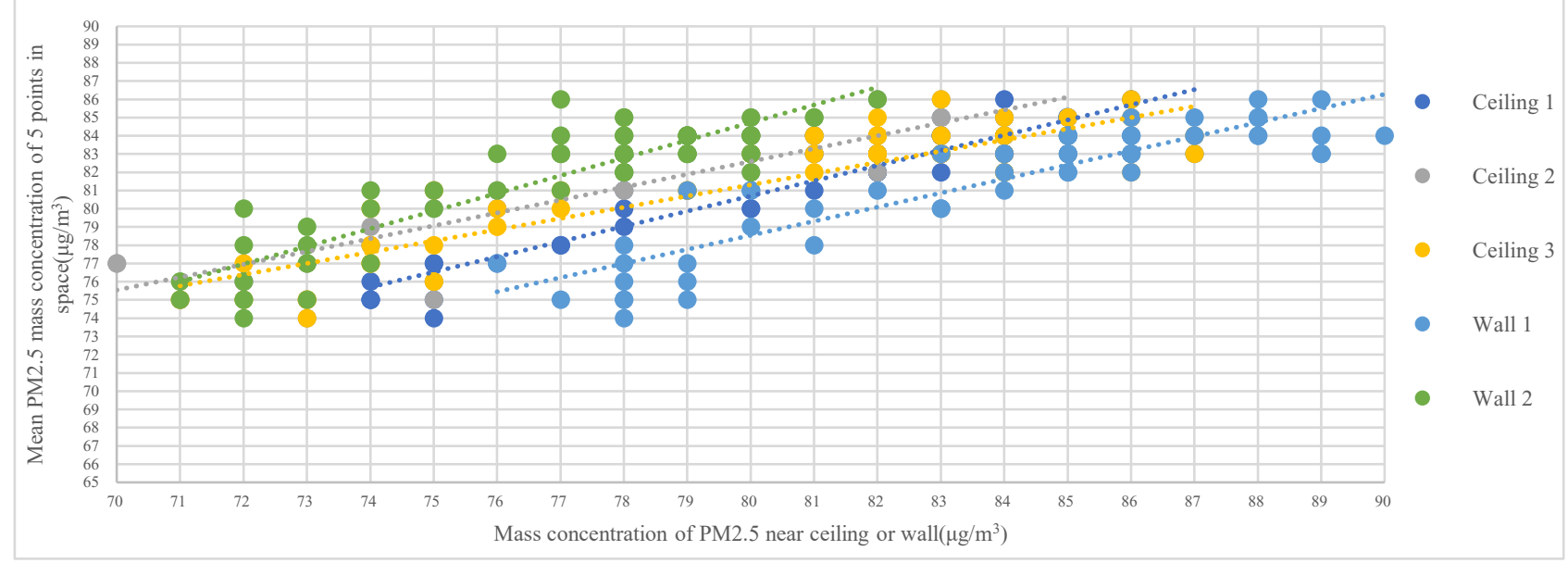

Figure 8. Linear regression between mass concentration of PM2.5 near ceiling or wall and mean value in space under condition 7

Table 4. Results of linear regression on condition 7

\begin{tabular}{cccc}
\hline & Slope & Intercept & $\mathrm{R}^{2}$ value \\
\hline Ceiling 1 & 0.8332 & 14.04 & 0.8854 \\
Ceiling 2 & 0.7049 & 26.197 & 0.7928 \\
Ceiling 3 & 0.6149 & 32.115 & 0.7942 \\
Wall 1 & 0.7732 & 16.684 & 0.8088 \\
Wall 2 & 0.9687 & 7.2234 & 0.8047 \\
\hline
\end{tabular}

Condition 8: burning the incense for the PM2.5 source with the velocity $=5.0 \mathrm{~m} / \mathrm{s}$ and temperature $=22{ }^{\circ} \mathrm{C}$ in inlet and no fresh air. In this condition, the linear relationship between mean PM2.5 mass concentration in space and
PM2.5 mass concentration of five points near wall or ceiling performs perfectly and the point "Wall 1" performs the best correlation among 5 points, which can be seen from Table 5 and its value of $\mathrm{R}^{2}$ is 0.9959 .

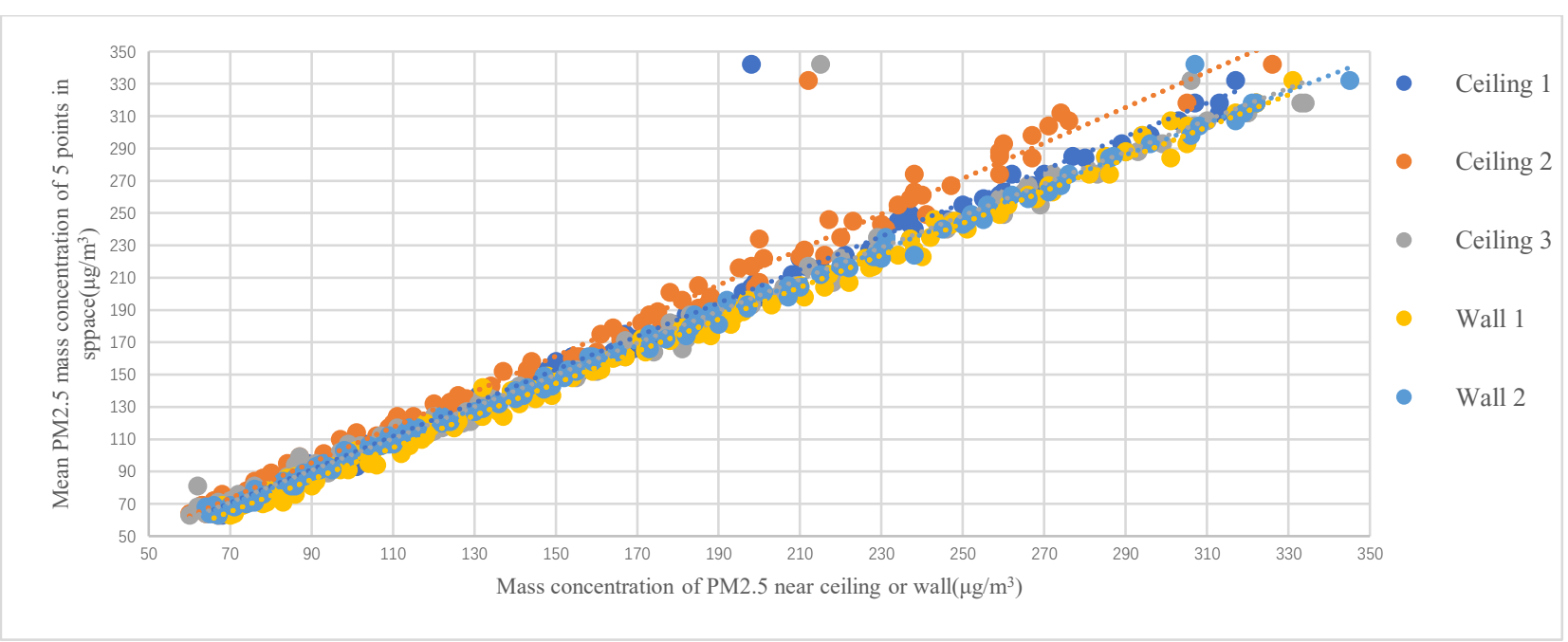

Figure 9. Linear regression between mass concentration of PM2.5 near ceiling or wall and mean value in space under condition 8

Table 5. results of linear regression on condition 8

\begin{tabular}{llll}
\hline & Slope & Intercept & $\mathrm{R}^{2}$ value \\
\hline Ceiling 1 & 1.0312 & -1.6316 & 0.9685 \\
Ceiling 2 & 0.986 & 1.8973 & 0.9705 \\
Ceiling 3 & 1.0999 & -3.6046 & 0.977 \\
Wall 1 & 0.9924 & -4.3395 & 0.9959 \\
\hline
\end{tabular}

\begin{tabular}{llll}
\hline Wall 2 & 0.9832 & 0.8746 & 0.9958 \\
\hline
\end{tabular}

\section{Conclusion}

After analysis, the following conclusions in this paper can be drawn:

1. When the indoor PM2.5 concentration is attenuated, the average value of the five monitoring points in the 
spatial respiration zone has a large linear correlation with the value of the wall monitoring point. From this paper, the point "Ceiling 1" and "Wall 1" would be the optimal locations for the monitoring of PM2.5 concentration in this office.

2. When the indoor environment parameters in the air conditioning are stable, the average value of the five monitoring points in the space breathing zone is close to the value of some wall monitoring points.

At present, some domestic scholars and foreign scholars have devoted themselves to the study of indoor PM2.5 distribution characteristics under different airconditioning systems. However, few researches have proposed reasonable monitoring points or monitoring criteria for indoor PM2.5. Therefore, this study is trying to fill the gap in this field.

By analyzing the indoor PM2.5 concentration distribution characteristics in the air conditioning system and reading the relevant references, the following innovations worth studying can be made:

(1) Conduct a typical personnel survey to analyze the effects of typical indoor personnel behavior on PM2.5 monitoring results and propose an indoor PM2.5 concentration distribution prediction model combined with experimental research and CFD simulation.

(2) Propose the air conditioning scheme optimization and design method based on indoor personnel PM2.5 inhalation risk as an evaluation index.

\section{Acknowledgements}

This research is supported by the National Key Research and Development Program of China (Grant No. 2017YFC0702704), the Fundamental Research Funds for the Central Universities (Project No. 106112015CDJXY210007), and the 111 Project (No.B13041)

\section{References}

1. Federal-Register. National ambient air quality standards for particulate matter. Fed. Regist, 1997, 62 (138).

2. Klepeis, N.E., Nelson, W.C., Ott, W.R., Robinson, J.P., Tsang, A.M., Switzer, P., et al.. The national human activity pattern survey (nhaps): a resource for assessing exposure to environmental pollutants[J]. Expo. Anal. Environ. Epidemiol, 200111 (3): 231252.

3. Leech, J.A., Nelson, W.C., Burnett, R.T., Aaron, S., Raizenne, M.E.. It's about time: a comparison of Canadian and American time-activity patterns[J]. Expo. Anal. Environ. Epidemiol, 2002 12: 427-432.

4. Robinson, J., Nelson, W.C.. National Human Activity Pattern Survey Data Base. USEPA, Research Triangle Park, NC, 1995.
5. Deng, Q., Lu, C., Ou, C., Chen, L., Yuan, H.. Preconceptional, prenatal and postnatal exposure to outdoor and indoor environmental factors on allergic diseases/symptoms in preschool children[J]. Chemosphere, 2016, 152: 459-467.

6. Lu, C., Deng, Q., Li, Y., Sundell, J., Norbäck, D.. Outdoor air pollution, meteorological conditions and indoor factors in dwellings in relation to sick building syndrome (sbs) among adults in China[Sci]. Total Environ, 2016, 560-561: 186-196.

7. Norbäck, D., Hashim, J.H., Markowicz, P., Cai, G., Hashim, Z., Ali, F., et al.. Endotoxin, ergosterol, muramic acid and fungal dna in dust from schools in Johor Bahru, Malaysia - associations with rhinitis and sick building syndrome (sbs) in junior high school students [Sci]. Total Environ, 2016, 545-546: 95-103.

8. Tunga Salthammer, Tobias Schripp, Erik Uhde, Michael Wensing. Aerosols generated by hardcopy devices and other electrical appliance[J]. Environment Pollution, 2012, 169: 167-174.

9. Antti J. Koivistoa, Tareq Hussein, Raimo Niemelä, Timo Tuomi, Kaarle Hämeri. Impact of particle emissions of new laser printers on modeled office room[J]. Atmospheric Environment, 2010, 44: 21402146.

10. K C Chung. Three-dimensional analysis of airflow and contaminant particle transport in a partitioned enclosure[J]. Building and environment, 1999, 34: 717.

11. Z. Zhang, Q. Chen. Experimental measurements and numerical simulations of particle transport and distribution in ventilated rooms[J]. Atmospheric environment, 2006, 40: 3396-3408.

12. Bin Zhao, Ying Zhang, Xianting Li, Xudong Yang, Dongtao Huang. Comparison of the modelling and the experimental results on[J]. Building and environment, 2004, 39: 1-8.

13. Z.F. Tian, J.Y. Tu, G.H. Yeoh, R.K.K. Yuen. On the numerical study of contaminant particle concentration in indoor airflow $[\mathrm{J}]$. Building and environment, 2006, 41: 1504-1514.

14. Yuting Ma, Yiqiang Jiang, Lan Li. Numerical Simulation of PM2.5 Distribution in Indoor Air[J]. Procedia engineering, 2015, 121: 1939-1947.

15. Zong Qingsong. Studies on Distribution and Deposition of Indoor Particulate Matter [D]. Anhui University of Technology, 2012.

16. Chen Jiwei. Numerical Simulation of Airflow and Tracks of Particles in Air-conditioned Room[D]. Nanjing University of Science \& Technology, 2007. 